\begin{tabular}{|l|r|}
\hline \multicolumn{1}{|c|}{ S sciendo } & \begin{tabular}{c} 
NCF $\begin{array}{l}\text { Nordic } \\
\text { Concrete } \\
\text { Federation }\end{array}$ \\
\hline $\begin{array}{l}\text { (C) Article authors. This is an open access article distributed under } \\
\text { the Creative Commons Attribution-NonCommercial-NoDerivs } \\
\text { licens. (http://creaticecommons.org/licenses/by.nc-nd/3.0/). }\end{array}$
\end{tabular} \\
\hline & $\begin{array}{r}\text { ISSN online 2545-2819 } \\
\text { ISSN print } \text { 0800-6377 }\end{array}$ \\
\hline DOI: $10.2478 /$ ncr-2020-0018 & $\begin{array}{r}\text { Received: Nov. 30, 2020 } \\
\text { Revision received: May 4, 2021 }\end{array}$ \\
& Accepted: May 5, 2021 \\
\hline
\end{tabular}

\title{
Effects of Slag Addition and Mechanical Pre-Processing on the Properties of Recycled Concrete in Terms of Compressive Strength and Workability
}

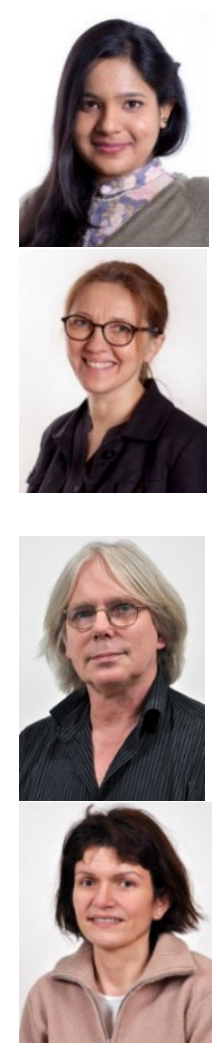

Madumita Sadagopan

Ph.D.,

Department of Resource Recovery and Building Technology,

University of Borås, 50190 Borås, Sweden

Email: madumita.sadagopan@hb.se

Katarina Malaga,

Adjunct Professor, Ph.D.,

Department of Resource Recovery and Building Technology, University of

Borås, 50190 Borås, Sweden.

RISE, CBI Swedish Cement and Concrete Research Institute, Borås, Sweden

Email: katarina.malaga@ri.se

Magnus Lundin

Ph.D.,Senior Lecturer,

Department of Resource Recovery

University of Borås, 50190 Borås, Sweden

Email: magus.lundin@hb.se

\section{Agnes Nagy}

Ph.D.,Senior Lecturer,

Department of Resource Recovery and Building Technology,

University of Borås, 50190 Borås, Sweden

Email: agnes.nagy@hb.se

\begin{abstract}
Concrete waste as crushed concrete aggregates (CCA) in structural concrete prolongs the technical life of the reference concrete accomplishing closed loop recycling. CCA concrete reaches the reference concrete compressive strength and workability by the densification of CCA and cement paste. Our previous study demonstrates CCA densification by mechanical pre-processing, aggregate quality improvements discerned by increased packing density giving reference concrete strength and workability. This study addresses paste densification with blast furnace slag (GGBS) to replace 30 (wt.\%) of Portland cement at reference concrete $\mathrm{w} / \mathrm{b}$ ratio 0.5 and a lower w/b 0.42 . Two CCA replacements are investigated: fine aggregates, CCA50; overall aggregate replacement, CCA100.
\end{abstract}


Compressive strength results show that both CCA50, CCA100 mixes achieve reference values at w/b 0.42 , only CCA100 achieves reference value at w/b 0.5 as a climate-optimized concrete. The CCA50 mix-w/b 0.5 reaches reference strength when paste densification by GGBS is combined with CCA densification from mechanical pre-processing of aggregates. The 7-day strength of CCA100 with GGBS increases by $11 \%$ by mixing with pre-soaked GGBS. Statistical analysis of CCA100 strength results shows significant improvements with GGBS compared to mechanical pre-processing. Significant improvements are possible in CCA50 mix for a combination of mechanical pre-processed aggregates and GGBS replacement.

Key words: Recycled concrete, $100 \%$ recycled aggregates, Supplementary cementitious materials, Blast furnace slag, Sustainability, Green concrete, climate-optimized concrete

\section{INTRODUCTION}

Concrete recycling achieves two important environmental goals: waste reduction and less extraction of virgin aggregates. The societal claims on circular economy and reducing carbondioxide emissions related to concrete is achieved by concrete recycling and by replacing cement with supplementary cementitious materials $[1,2]$. Crushed concrete aggregates (CCA) originating from structural concrete completes a closed-loop recycling when reused in structural concrete. In Sweden, such conventional recycling covers only $6 \%$ of the mineral waste fractions generated every year [3]. Despite observed recurring increase in mineral waste used in backfilling and landfill construction, no corresponding increase is found in conventional recycling in structural concrete. More conventional recycling is possible by improving CCA quality and adjusting concrete recipes to include CCA [4-6].

These challenges with conventional concrete recycling may be met by improving CCA density, densifying the cement paste and the interface in between resulting in concrete recipes adjusted for CCA inclusion. The adhered mortar on CCA lowers density and increases water absorption [7, 8]. One such improvement is mechanical pre-processing of CCA where adhered mortar is dislodged from CCA by abrasion leading to densified CCA, which is shown to result in compressive strength at reference level [9]. However, in the case of low-density CCA, mechanical pre-processing alone is not sufficient to reach the reference strength [5]. Besides mechanical pre-processing, CCA concrete strength gain maybe achieved by SCM addition. For example, introducing GGBS at 50\%, silica fume at $15 \%$ by weight of binder content increases compressive strength with $50 \%$ for concrete with coarse CCA and overall aggregate replacement respectively $[10,11]$.

SCMs are classified based on their reactivity as latent hydraulic such as blast furnace slag (GGBS) and pozzolanic such as fly ash, silica fume and activated glass powder [12]. The addition of SCM is leading to reaction at two levels: hydration reaction and pozzolanic reaction. For example, GGBS being latent hydraulic material uses $\mathrm{Ca}(\mathrm{OH})_{2}$ or other alkali activators to initiate reactivity. This is shown in Equation 1 by the hydration of Portland clinker $\left(\mathrm{C}_{3} \mathrm{~S}\right)$ to build up cement gel $(\mathrm{C}-\mathrm{S}-\mathrm{H})$ and $\mathrm{Ca}(\mathrm{OH})_{2}$, noted $\mathrm{CH}$. As $\mathrm{CH}$ is formed, the SCM constituents (S) react in the secondlevel reaction and builds up new cement gel, according to Equation 2. 


$$
\begin{aligned}
& \mathrm{C}_{3} \mathrm{~S}+\mathrm{H} \rightarrow \mathrm{C}-\mathrm{S}-\mathrm{H}+\mathrm{CH} \\
& \mathrm{CH}+\mathrm{S}+\mathrm{H} \rightarrow \mathrm{C}-\mathrm{S}-\mathrm{H}
\end{aligned}
$$

As the pozzolanic reaction is dependent on the formation of $\mathrm{CH}$ means that the strength development from pozzolanic reaction is delayed [13]. As a chemical effect, the SCM consumes $\mathrm{CH}$ to build cement gel, which is the most strength-building component in cement hence affecting concrete strength positively [14]. Besides oxides of silica, SCM such as GGBS also contains oxides of calcium and aluminium, denoted therefore as C-A-S and requires calcium hydroxide only for the activation of its hydraulic properties. Equation 3 shows the reaction with GGBS to form cement gel products.

$$
\mathrm{C}-\mathrm{A}-\mathrm{S}+\mathrm{H} \rightarrow \mathrm{C}-\mathrm{S}-\mathrm{H}+\mathrm{C}-\mathrm{A}-\mathrm{H}+\mathrm{C}-\mathrm{A}-\mathrm{S}-\mathrm{H}
$$

The early strength gain is usually delayed in the case of concrete containing pozzolanic materials, however previous research has shown that surface-coating and mixing techniques improve the early age strength. For example, in the case of activated glass powder, soaking in water for 8 hours before concrete mixing leads to the formation of free ions of calcium and sodium boosting the building of cement gel by pozzolanic reaction and leading to early strength gain [15]. Along with pozzolanic effect, SCM such as GGBS densifies microstructure between aggregate and cement paste by a possible micro-filler effect (particles $<1 \mu \mathrm{m}$ ) leading to better transfer of stresses between paste and aggregate $[6,16]$. The micro-filler effect is related to larger specific surface and consequently to a small size of SCM such as silica fume; indirectly observed by increased early age strength compared to pozzolanic effect which sets in after hydration begins.

A micro-filler effect on a level of CCA pores is pursued by Katz [6] using SEM imagery to show denser micro-structure of CCA surface after silica fume impregnation showing $30 \%$ increase in 7-day compressive strength. Similarly, surface coating is integrated in concrete mixing when partially wetted CCA is mixed with GGBS before other mix constituents are added resulting in $18 \%$ increase in the 7-day strength of CCA concrete. The densification of the interface by microfiller effect is shown with microscopic imagery [17].

Amount of CCA replaced influences the compressive strength of CCA concrete with SCM addition, inferred from literature. A larger increase in strength is seen with fly ash addition when CCA replaces $100 \%$ of coarse aggregates compared to $50 \%$ [18]. This is observed for different water/cement ratios. Similar trends are seen for concrete when GGBS replaces 55\% of cement [19]. This shows that SCM addition is more beneficial in strength improvements for concrete with higher CCA replacements [9]. Similar studies in literature reason that SCM is more effective in mixes with higher CCA replacement as the volume of adhered mortar is larger for the SCM to densify in virtue of its reactivity and specific surface $[17,19]$.

Mechanical pre-processing CCA is shown to influence strength of CCA concrete with SCM. For example, due to CCA quality improvements induced by mechanical pre-processing, concrete with $20 \%$ glass powder shows higher 28-day compressive strength at $40 \%$ coarse CCA 
replacement than at 20\% CCA without mechanical pre-processing [20]. Mechanical preprocessing is leading to an increased packing-density, which together with cement paste densification by SCM further benefits concrete strength $[5,9]$.

Most investigations compare the performance of CCA concrete with SCM keeping same waterbinder ratio as the reference concrete, meaning, replacing of original cement by a part of SCM leading to reduced embodied carbon relating to a more climate optimized concrete. [19, 21]. Same water-binder ratio ensures common ground to compare the performance of concrete with different SCM capacity of building cement gel compared to reference cement.

Water/binder ratios are lowered as a consequence when SCM is proportioned as an addition to cement amount in the reference concrete. Kou S.C. et al. [18] firstly replace cement with SCM, however not reaching reference concrete strength, therefore lower water/binder ratio by adding SCM. Other ways of producing lower water/binder ratios with SCM is to increase the cement content across the mixes; therefore counteracting climate optimized solutions by increasing embodied carbon $[18,22,23]$. All of these is applied for constant water content. A short review on SCM proportioning in CCA concrete is shown in Table 1 including even studies which use a part of the SCM to replace fine aggregates.

Table 1 - Classification of SCM proportioning in CCA concrete, literature review

\begin{tabular}{|c|c|c|c|}
\hline \multirow{2}{*}{ Scenario } & Same w/b ratio as reference & \multicolumn{2}{c|}{ Reduced w/b ratio from reference } \\
\cline { 2 - 4 } & \% replacement of cement & $\%$ of binder & $\begin{array}{c}\text { \% of fine aggregate } \\
\text { replacement }\end{array}$ \\
\hline \multirow{3}{*}{ Fly ash } & $\begin{array}{c}\text { Variation of fly ash replacement of } \\
\text { cement from } 25,35 \% \text { according to } \\
{[22], \text { to } 50 \%[10] \text { and } 35 \%[19],}\end{array}$ & $\begin{array}{c}25 \%[18], \\
30 \%[24], \\
20.5 \%[25]\end{array}$ & $30 \%[11]$ \\
\hline $\begin{array}{c}\text { Activated glass } \\
\text { powder }\end{array}$ & $20 \%[21], 10-30 \%[20,26]$ & & $90 \%[26]$ \\
\hline GGBS & $50-70 \%[10], 55 \%[19], 60 \%[27]$ & $35 \%, 70 \%[28]$ & \\
\hline Silica fume & $10 \%[19]$ & $10 \%[24]$ & $15 \%[11]$ \\
\hline Flyash + GGBS & $25 \%$ each $[10]$ & & \\
\hline
\end{tabular}

Concrete durability is influenced by the structure of hardened cement paste with reference to its porosity, although not addressed in this study; a short literature review discusses effect of mechanical pre-processing and SCM addition. The durability aspects discussed are resistance to chloride, drying shrinkage and carbonation, freeze-thaw is not discussed as this study investigates indoor concrete. Porosity of cement paste is made up of gel pores and capillary pores; the gel pores are extremely fine and dispersed compared to capillary pores [29].

Introducing GGBS in concrete reduces the porosity of cement paste with densification through conversion of $\mathrm{Ca}(\mathrm{OH})_{2}$ to cement gel and by modifying pore size to become finer [30]. Powers [31] shows that a decrease in capillary porosity will induce a major reduction of coefficient of permeability. A reduction of the coefficient of permeability is observed in concrete containing a combination of $25 \%$ fly ash and $25 \%$ GGBS [10]. 
CCA consists of porous adhered mortar showing increased permeability already with its relatively higher water absorption capacity than natural aggregates. However, GGBS or silica fume densifies adhered mortar and the cement-CCA interface owing to larger specific surface/smaller size than Portland cement, therefore mitigating permeability issues arising from CCA porosity.

Resistance to chloride in CCA concrete with GGBS is seen in literature, for example, a 30\% reduction in chloride ions passage is seen in concrete with coarse CCA when GGBS replaces 55\% of the Portland cement [19]. Khodair et al. [32] investigate chloride permeability of concrete with different CCA replacement percentages with 50\% GGBS replacement and show that chloride permeability reduces with increasing CCA replacement percentage. This can be explained by the fact that GGBS is most efficient on cement paste densification for high CCA replacement percentages. Also, GGBS has the potential to bind chlorides thus mitigating the dissolution of chloride ions in pore water which reduce $\mathrm{pH}$ level in concrete [23].

Drying shrinkage in CCA concrete is higher than concrete with natural aggregates due to the reduced restraint of CCA arising from adhered mortar content. Drying shrinkage is seen to increase with increasing CCA content $[18,33]$. Densifying CCA by mechanical pre-processing is a beneficial tool for reducing drying shrinkage by reduction of the adhered mortar content. Studies show reduction in drying shrinkage in concrete even by adding SCM and attribute this to the restraining effects of densified cement paste [19]. At low water/cement ratio the effect of amount of CCA replacement overrides the effect of SCM addition, thus in this case adhered mortar removal by mechanical pre-processing would be more beneficial than SCM [18]. Concrete with coarse CCA shows higher drying shrinkage than reference concrete; with 55\% GGBS, drying shrinkage is lowered to the level of reference concrete for both 50 and 100\% CCA replacements [19]. Drying shrinkage is reduced by $13.5 \%$ with $50 \%$ combined replacement of fly ash and GGBS in self-compacted concrete with a full replacement of coarse CCA [34].

In the case of carbonation carbon dioxide usually reacts with $\mathrm{CH}$, however by introducing $\mathrm{SCM}$ it reacts with C-S-H to form silica gel which due to high porosity facilitates further carbonation [13]. Previous studies show increase in carbonation depth despite reduced CCA porosity consequent of SCM due to the exhaustion of alkaline reserve in the concrete. However, CCA can have excessive alkaline content due to the presence of adhered mortar therefore still having sufficient resistance for carbonation [35]. If there is a need to behold the positive effect of the presence of adhered mortar, then the mechanical pre-processing of CCA is not advisable.

This study investigates GGBS to substitute $30 \%$ Portland cement in CCA concrete to achieve compressive strength and workability matching the quality of structural concrete of exposure class $\mathrm{X} 0$, reference concrete in this study. Two CCA replacements are investigated, CCA100 where CCA replaces both fine and coarse aggregates; CCA50 where only fine aggregates are replaced. Synergistic effects of aggregate and cement paste densification is investigated by SCM additions in concrete with mechanically pre-processed CCA for both CCA replacements, denoted by MPCCA100, MPCCA50, respectively. 


\section{2.}

\section{MATERIALS AND METHODS}

Our previous study pursues the fraction-wise mechanical pre-processing of coarse and fine CCA by revolving for 15 minutes in a horizontal rotating drum with ribs. The CCA is then washed on sieves to remove the dislodged adhered mortar [9]. This results in improvement in CCA density and shape discernible in increased packing density of the combined coarse and fine CCA fractions. After mechanical pre-processing, the pre-soaking water amount corresponding to 15-minute water absorption value of combined coarse and fine CCA fraction is added in pre-processing stage before concrete mixing [4]. Sequential mixing method makes cement bind directly on the presoaked CCA to benefit strengthening of the interface between aggregate and cement paste. The mechanical and pre-soaking pre-processing together result in MPCCA100 and MPCCA50 to reach compressive strength and workability of reference concrete. The compressive strength and workability of MPCCA50, MPCCA100 concrete are seen to increase with aggregate packing density which works as a bridging property between aggregate and concrete properties [9].

This study investigates GGBS replacements at two water/binder ratios in three scenarios, Scenario A with same water-binder ratio as reference concrete 0.5 ; scenario $\mathrm{B}$ has a reduced water-binder ratio, 0.42. Scenario $\mathrm{C}$ shows the potential of replacing Portland cement and fine aggregates with GGBS in CCA100 concrete. Table 2 presents the investigated CCA mixes; with GGBS denoted by (S30, S70); mechanically pre-processed CCA by (MPCCA50, MPCCA100). The mixes S30MPCCA50, S30MPCCA100 investigate both pre-processing and GGBS replacement in concrete with 50,100\% CCA respectively. REF stands for reference concrete mix.

Table 2 - CCA concrete mixes with GGBS

\begin{tabular}{|c|c|c|c|c|c|c|c|}
\hline \multirow{3}{*}{$\begin{array}{c}\text { Scenario } \\
\text { Ref. }\end{array}$} & \multirow{3}{*}{$\begin{array}{c}\text { Cement/ } \\
\text { GGBS } \\
\text { Portland } \\
\text { cement }\end{array}$} & \multirow{3}{*}{\begin{tabular}{c|}
$\mathrm{w} / \mathrm{b}$ \\
0.5
\end{tabular}} & \multicolumn{5}{|c|}{ Concrete mixes denoted } \\
\hline & & & \multirow{2}{*}{$\begin{array}{c}\begin{array}{c}\text { Reference } \\
\text { aggregates }\end{array} \\
\text { REF }\end{array}$} & \multicolumn{2}{|c|}{$\begin{array}{l}\text { CCA replacements } \\
\quad(50 \%, 100 \%)\end{array}$} & \multicolumn{2}{|c|}{$\begin{array}{c}\text { Mechanically pre-processed } \\
\text { CCA }\end{array}$} \\
\hline & & & & CCA100 & CCA50 & MPCCA100 & MPCCA50 \\
\hline A & GGBS30\% & 0.5 & \multirow{2}{*}{ S30REF } & \multirow{2}{*}{ S30CCA100 } & \multirow{2}{*}{ S30CCA50 } & \multirow{2}{*}{ S30MPCCA100 } & \multirow{2}{*}{ S30MPCCA50 } \\
\hline B & GGBS30\% & 0.42 & & & & & \\
\hline $\mathrm{C}$ & GGBS70\% & 0.42 & & S70CCA100 & & & \\
\hline
\end{tabular}

Additionally, improvements in the early-age strength of CCA100 concrete is investigated by an improved mixing technique by pre-soaking GGBS in water for 8 hours before it is added to CCA in the mixing process. 


\section{1}

\section{SCM characterization}

The cement used in this study is CEM II/A-LL 42.5R containing about $87 \%$ clinker, $13 \%$ limestone filler and other minor constituents. The GGBS is a commercial product, Merit 5000, produced by grinding and rapid water-cooling blast furnace slag in a ball mill in Sweden.

The details of oxide composition and physical properties such as density, specific surface (Blaine fineness) of CEM II/A-LL 42.5R and GGBS are shown in Table 3 and acquired from the respective product specifications [36, 37]. Figure 1 shows the particle size distribution of GGBS to be of smaller size than Portland cement correlating with larger specific surface. These properties may together contribute to a high densification capacity of the GGBS related to building cement gel and micro-filler effect.

Table 3 - Chemical composition and physical properties of SCM

\begin{tabular}{|c|c|c|c|c|c|c|c|}
\hline \multirow{2}{*}{ SCM } & \multicolumn{4}{|c|}{ Chemical composition $(\%)$} & \multirow{2}{*}{$\begin{array}{l}\text { Specific } \\
\text { surface } \\
\left(\mathrm{m}^{2} / \mathrm{kg}\right)\end{array}$} & \multirow{2}{*}{$\begin{array}{c}\text { Compact } \\
\text { density } \\
\left(\mathrm{kg} / \mathrm{m}^{3}\right)\end{array}$} & \multirow{2}{*}{ 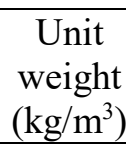 } \\
\hline & $\mathrm{CaO}$ & $\mathrm{SiO}_{2}$ & $\mathrm{Al}_{2} \mathrm{O}_{3}$ & $\mathrm{Fe}_{2} \mathrm{O}_{3}$ & & & \\
\hline CEM II/A-LL & 61.4 & 18.7 & 3.9 & 2.8 & $430-510$ & 3080 & 1250 \\
\hline GGBS & 31 & 34 & 12 & 0.3 & $460-540$ & $\begin{array}{c}2800- \\
3000\end{array}$ & 1138 \\
\hline
\end{tabular}

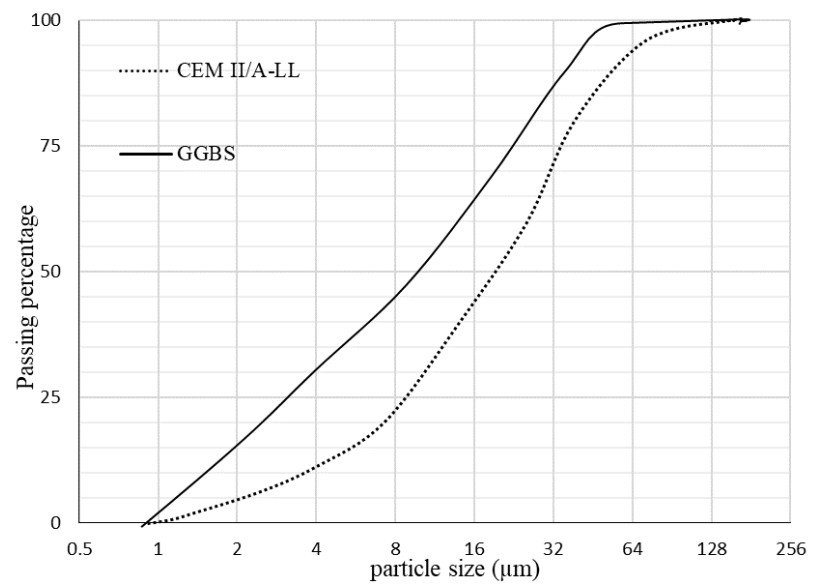

Figure 1-Particle size distributions of SCM

\section{2}

Aggregate characterization

The CCA investigated in this study originates from the prefabricated rejects of an industrially active concrete recipe of grade $\mathrm{C} 40 / 50$, also the reference concrete recipe in this study. Reference aggregates are crushed stone of size $8 / 11.2 \mathrm{~mm}$ and naturally graded aggregate $0 / 8 \mathrm{~mm}$. The CCA fractions are $8 / 11.2 \mathrm{~mm}, 0.5 / 4 \mathrm{~mm}$ and $0 / 4 \mathrm{~mm}$ produced by crushing concrete rubble in a jaw crusher and with adjusted grading to reference, Figure 2. With the goal to densify the CCA by adhered mortar removal, CCA is mechanically pre-processed for 15 minutes, workflow in figure 3. The grading curves of pre-processed CCA are matched to reference concrete aggregates by adjusting the proportions of CCA fractions to receive workability similar to reference concrete [13], combined grading curves in Figure 2. The packing density is calculated as the weighed sum of unit weights of individual CCA fractions participating in the concrete mix. It assembles the 
collaborative effects of aggregate properties and increases with mechanical pre-processing of CCA, it is indicative of CCA quality [9].

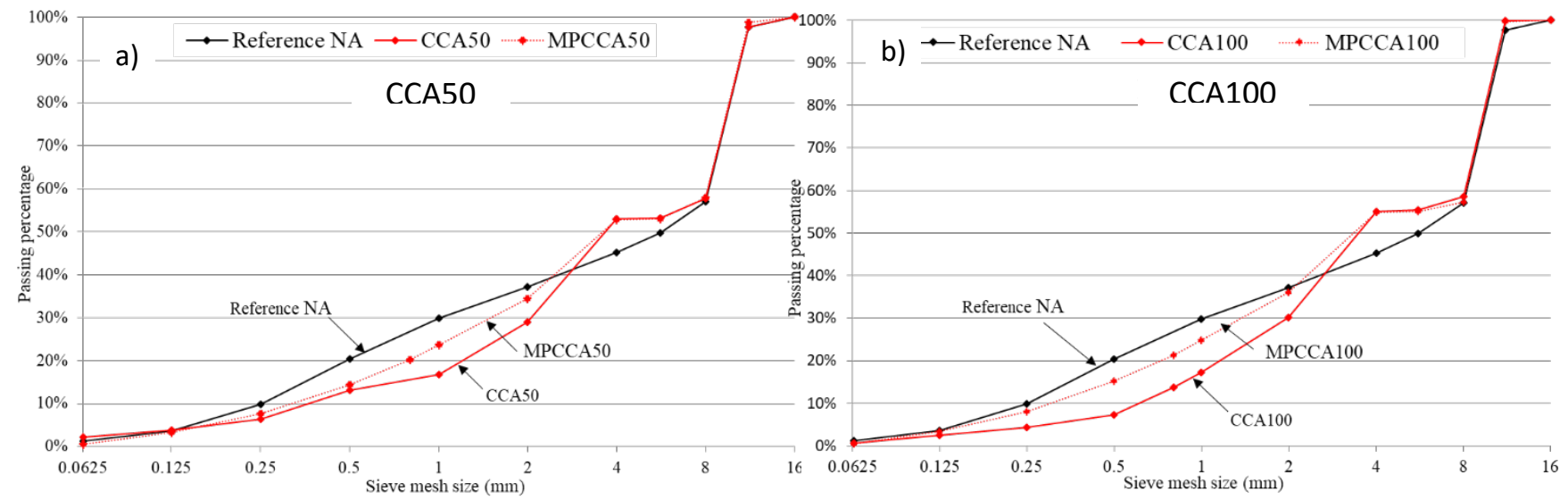

Figure 2 - Particle size distributions of CCA

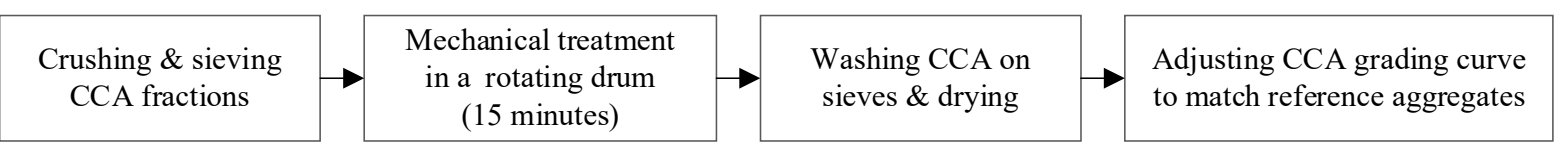

Figure 3 - Workflow- modifications to CCA

Mechanical pre-processing enhances physical properties such as apparent density, unit weight compared to CCA without pre-processing, see Table 4. The water absorption of the CCA is measured at 15 minutes on a combined fraction consisting of coarse and fine CCA by the modified pycnometer method [4]. CCA water absorption reduces with adhered mortar removal caused by mechanical pre-processing; it is however higher for MPCCA50 due to readjustments in the proportioning of CCA after mechanical pre-processing.

Table 4 - Properties of aggregates

\begin{tabular}{|c|c|c|c|c|c|c|}
\hline \multirow[b]{2}{*}{ Properties } & \multicolumn{2}{|c|}{ Reference aggregate } & \multirow{2}{*}{$\begin{array}{c}\text { Pre- } \\
\text { processing } \\
\text { alternatives }\end{array}$} & \multicolumn{3}{|c|}{$\mathrm{CCA}$} \\
\hline & $0 / 8$ & $8 / 11.2$ & & $\begin{array}{c}0 / 4 \\
\mathrm{CCA} \\
\end{array}$ & $0.5 / 4 \mathrm{CCA}$ & $\begin{array}{c}8 / 11.2 \\
\mathrm{CCA}\end{array}$ \\
\hline \multirow{2}{*}{ Unit weight $\left(\mathrm{kg} / \mathrm{m}^{3}\right)$} & 1837 & 1486 & $\mathrm{CCA}$ & 1475 & 1263 & 1249 \\
\hline & - & - & MPCCA & 1464 & 1299 & 1336 \\
\hline \multirow{2}{*}{ Void content (\%) } & 32 & 44.4 & CCA & 45.6 & 53.6 & 52.7 \\
\hline & - & - & MPCCA & 44.8 & 48.5 & 49.0 \\
\hline \multirow{3}{*}{$\begin{array}{c}\text { Apparent density } \\
\left(\mathrm{kg} / \mathrm{m}^{3}\right)\end{array}$} & 2701 & 2720 & $\mathrm{CCA}$ & 2712 & 2720 & 2640 \\
\hline & - & - & MPCCA & 2614 & 2527 & 2621 \\
\hline & \multicolumn{2}{|c|}{ Reference aggregate } & \multicolumn{4}{|c|}{ Combined CCA fractions } \\
\hline \multirow{2}{*}{$\begin{array}{l}\text { Packing density- } \\
\left(\mathrm{kg} / \mathrm{m}^{3}\right)\end{array}$} & \multicolumn{2}{|c|}{1672} & CCA50 & 1410 & CCA100 & 1299 \\
\hline & \multicolumn{2}{|c|}{ 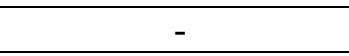 } & MPCCA50 & 1454 & MPCCA100 & 1377 \\
\hline \multirow{2}{*}{$\begin{array}{c}\text { Combined water } \\
\text { absorption }(\%)\end{array}$} & \multirow{2}{*}{\multicolumn{2}{|c|}{-}} & CCA50 & 2.8 & CCA100 & 5.7 \\
\hline & & & MPCCA50 & 3.6 & MPCCA100 & 4.5 \\
\hline
\end{tabular}




\subsection{Concrete mixing}

Before mixing the CCA are pre-processed by momentary pre-soaking with water based on the 15minute water absorption value of the combined CCA fraction determined by the modified pycnometer method $[4,17]$. The concrete mixing comprises a stage-by-stage addition of mixing water and superplasticizer to the mixture of pre-soaked CCA, cement and GGBS, to enable a coating on the CCA and strengthen the interface. By a stage-wise addition of mixing water the aggregate-paste gets coated simultaneously during concrete mixing [38]. To enhance the earlyage strength of CCA100 concrete containing GGBS, this study follows an improved mixing method [15] where the GGBS is soaked with 30\% mixing water and superplasticizer for 8 hours before it is added to the dry mixing contents. Mixing method is seen in Figure 4. A polycarboxylate based superplasticizer with dry content $24 \pm 1 \mathrm{wt}$ \% is used in concrete recipe; mentioned in Table 5 with other mix constituents.

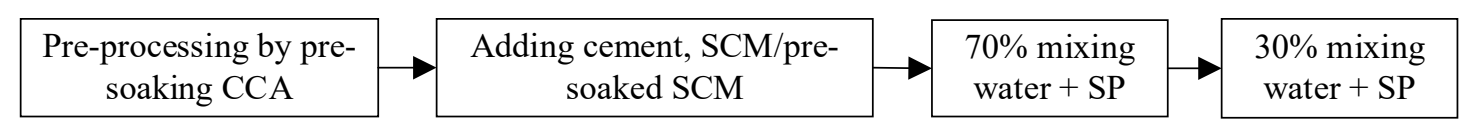

Figure 4 - Workflow- mixing method for CCA concrete

Table 5 - Concrete recipes for mixes with, without GGBS

\begin{tabular}{|c|c|c|c|c|c|c|c|c|c|c|c|c|}
\hline \multirow[b]{4}{*}{ Mixes } & \multicolumn{12}{|c|}{ Mix constituents $\left(\mathrm{kg} / \mathrm{m}^{3}\right)$} \\
\hline & \multicolumn{2}{|c|}{ GGBS } & \multicolumn{2}{|c|}{ Cement } & \multirow{3}{*}{$\begin{array}{l}\text { Mix } \\
\text { water }\end{array}$} & \multirow{3}{*}{ SP } & \multirow{3}{*}{$\begin{array}{c}\text { Pre- } \\
\text { soak } \\
\text { water }\end{array}$} & \multirow{2}{*}{\multicolumn{3}{|c|}{ CCA }} & \multirow{2}{*}{\multicolumn{2}{|c|}{$\begin{array}{l}\text { Reference } \\
\text { aggregate }\end{array}$}} \\
\hline & \multirow[b]{2}{*}{$\begin{array}{l}\mathrm{w} / \mathrm{b} \\
0.42\end{array}$} & \multirow[b]{2}{*}{$\begin{array}{c}\mathrm{w} / \mathrm{b} \\
0.5\end{array}$} & \multirow[b]{2}{*}{$\begin{array}{l}\mathrm{w} / \mathrm{b} \\
0.42\end{array}$} & \multirow[b]{2}{*}{$\begin{array}{c}\mathrm{w} / \mathrm{b} \\
0.5\end{array}$} & & & & & & & & \\
\hline & & & & & & & & $\begin{array}{l}0 / 4 \\
\mathrm{~mm}\end{array}$ & $\begin{array}{c}0.5 / 4 \\
\mathrm{~mm}\end{array}$ & $\begin{array}{c}8 / 11.2 \\
\mathrm{~mm}\end{array}$ & $\begin{array}{l}0 / 8 \\
\mathrm{~mm}\end{array}$ & $\begin{array}{c}8 / 11.2 \\
\mathrm{~mm}\end{array}$ \\
\hline $\begin{array}{l}\text { Reference } \\
\text { concrete } \mathrm{w} / \mathrm{c} \\
0.5\end{array}$ & - & - & - & 490 & 245 & 3.7 & - & - & - & - & 845 & 729 \\
\hline S30REF & 151 & 147 & 431 & 343 & 245 & 3.7 & - & - & - & - & 845 & 729 \\
\hline S30CCA100 & 151 & 147 & 431 & 343 & 245 & 3.7 & 44.86 & 314.8 & 550.9 & 708.3 & - & - \\
\hline $\begin{array}{l}\text { S30MPCCA } \\
100\end{array}$ & 151 & 147 & 431 & 343 & 245 & 3.7 & 36.2 & 708.3 & 157.4 & 708.3 & - & - \\
\hline S30CCA50 & 151 & 147 & 431 & 343 & 245 & 3.7 & 24.08 & 314.8 & 519.4 & - & - & 729 \\
\hline $\begin{array}{l}\text { S30MPCCA } \\
50\end{array}$ & 151 & 147 & 431 & 343 & 245 & 3.7 & 24.09 & 676.8 & 157.4 & - & - & 729 \\
\hline & $\begin{array}{l}\mathrm{w} / \mathrm{b} \\
0.42\end{array}$ & & & & & & & $\begin{array}{c}0 / 4 \mathrm{~mm} \\
\text { CCA } \\
/ \text { GGBS }\end{array}$ & & & & \\
\hline S70CCA100 & 151 & & 431 & & 245 & 4.4 & 38.6 & $\begin{array}{l}119.8 \\
1195 \\
\end{array}$ & 550.9 & 708.3 & - & - \\
\hline
\end{tabular}

Following the mixing process, the workability of the fresh concrete is determined by measuring the slump and flow diameter, according to SS-EN 12350-5. Three cylinder specimens of size $100 \mathrm{~mm} \times 200 \mathrm{~mm}$ are cast, demoulded after 24 -h and cured for 28 days submerged in a curing tank with water at $20 \pm 2{ }^{\circ} \mathrm{C}$ according to SS- EN 12390-2. Compressive strength is tested according to SS EN 12390-3 at 7 and 28 days. 


\section{3.}

\section{RESULTS AND DISCUSSION}

This research investigates modification techniques presented earlier, implementing them on aggregate, cement paste and concrete mixing levels. These modifications jointly contribute to CCA concrete to give workability and compressive strength comparable to reference concrete by beneficial effects shown in Figure 5.

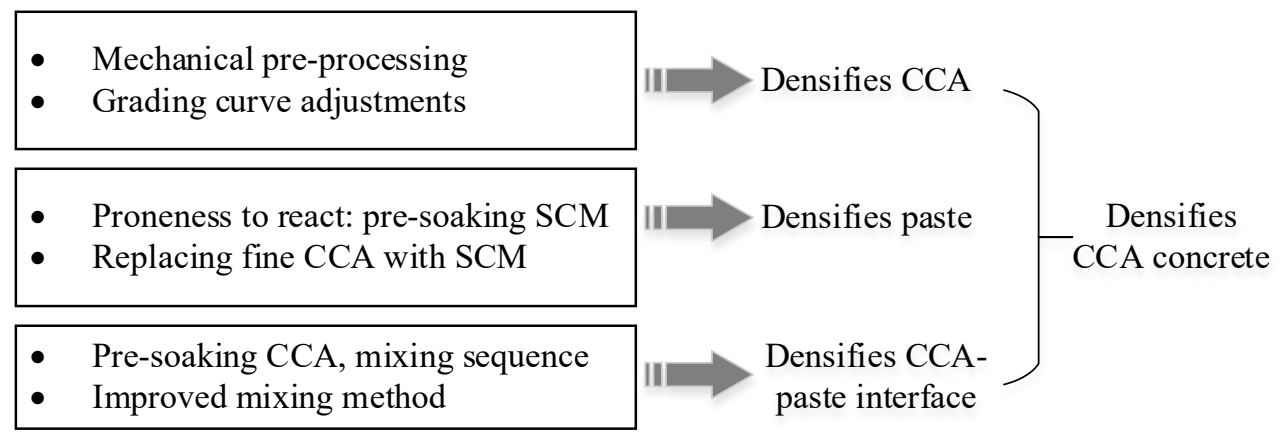

Figure 5 - Modification tools for CCA concrete

\section{1}

\section{Workability}

The mechanically pre-processed CCA has a higher packing density $\left(1377 \mathrm{~kg} / \mathrm{m}^{3}\right)$ and demands lesser compaction compared to un-preprocessed CCA $\left(1299 \mathrm{~kg} / \mathrm{m}^{3}\right)$ therefore benefitting strength without compromising stability. With GGBS, the un-preprocessed CCA concrete shows more stability during compaction in comparison to Portland cement; more apparent with $\mathrm{w} / \mathrm{b}$ ratio 0.42 .

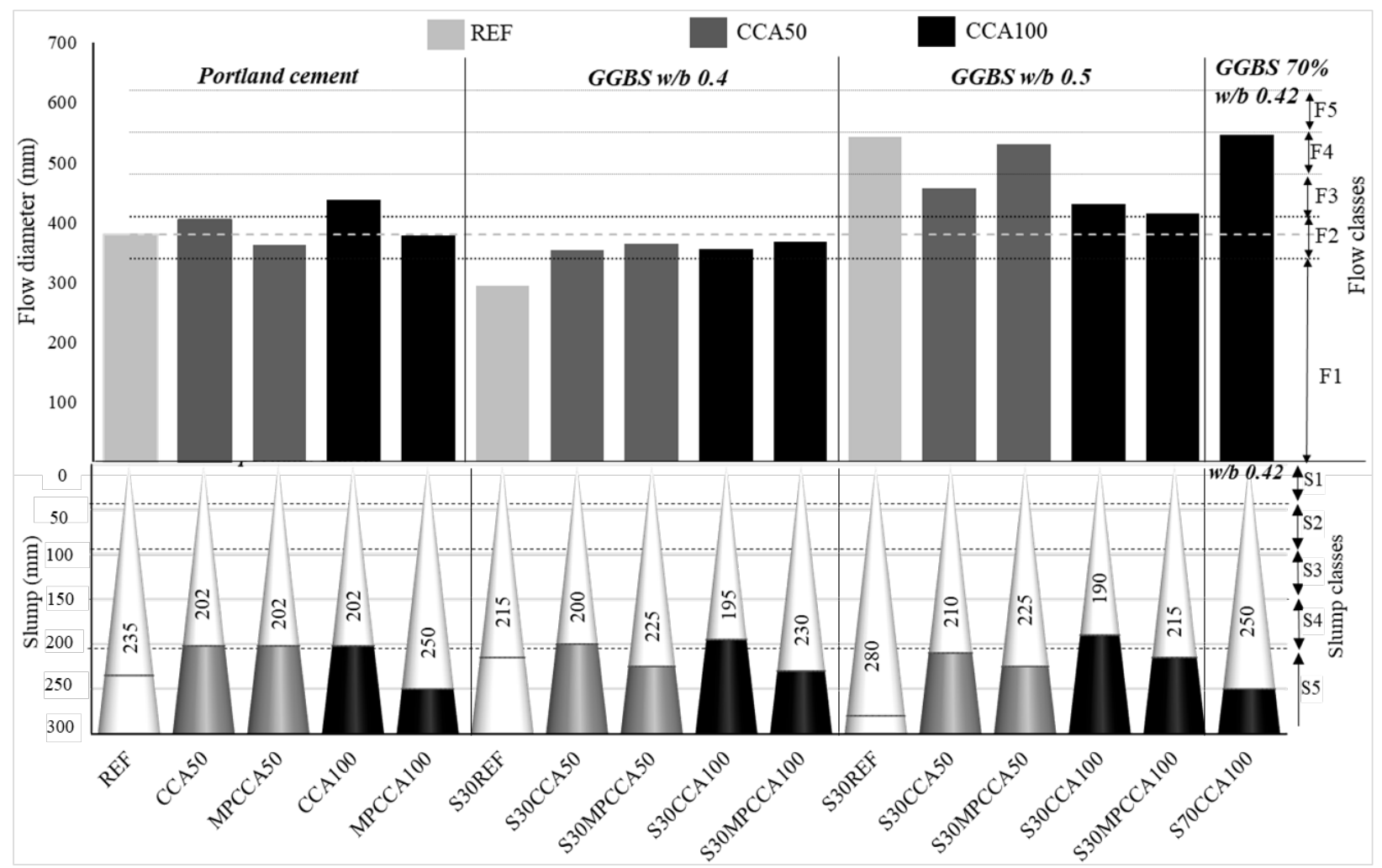

Figure 6-Workability of concrete mixes with GGBS. Above: flow diameter, below: slump test 
For all CCA replacements, GGBS concrete with same water/binder ratio 0.5 results in slightly increased flow diameter belong to flow classes F3 and above, compared to reference concrete showing F2, see Figure 6 . However, at lower water/binder ratio 0.42 , the flow diameter values are in the range of F2 class. This is in agreement with previous research, showing that GGBS has a water-reducing quality such that workability of GGBS concrete resembles workability of concrete with more mixing water [23]. The slump results are consistent with the flow diameters of respective mixes, such that higher slump seen in 0.5 water/binder ratio reduces with 0.42 ratio.

Mix S70CCA100 with flow diameters in F4, Figure 6, is slightly less than that of self-compacting concrete (F5 and above), it is a result of increase in fines content lesser than $600 \mu \mathrm{m}$ due to a larger addition of GGBS [13]. Previous research shows that CCA can be adapted to selfcompacted concrete with GGBS at 50\% replacement of Portland cement [32, 39]. Mixes like S70CCA100 with mechanically pre-processed CCA could yield a concrete likening selfcompacted concrete due to improvements in CCA quality brought about by pre-processing.

\section{2}

\section{Density of hardened concrete}

CCA densification by mechanical pre-processing increases packing density of CCA, leading to an increase in the hardened concrete density of CCA50 and CCA100, shown in our previous study [9]. This is also seen for all alternatives with GGBS, Figure 7.

Although having the lowest packing density of all replacement alternatives, CCA100 concrete density with GGBS reaches MPCCA100 density. Thus, an un-preprocessed CCA gets the benefits of the SCM and matches the performance of MPCCA concrete especially for $100 \%$ CCA replacement. Densification of cement paste is due to the elevated cement-gel building capacity of GGBS combined with probable micro-filler effect or effect of coating on un-preprocessed CCA [6]. Concrete density enhancement with SCM addition is in agreement with previous research where CCA100 concrete density increases by $6 \%$ when fly ash replaces $30 \%$ cement [40].

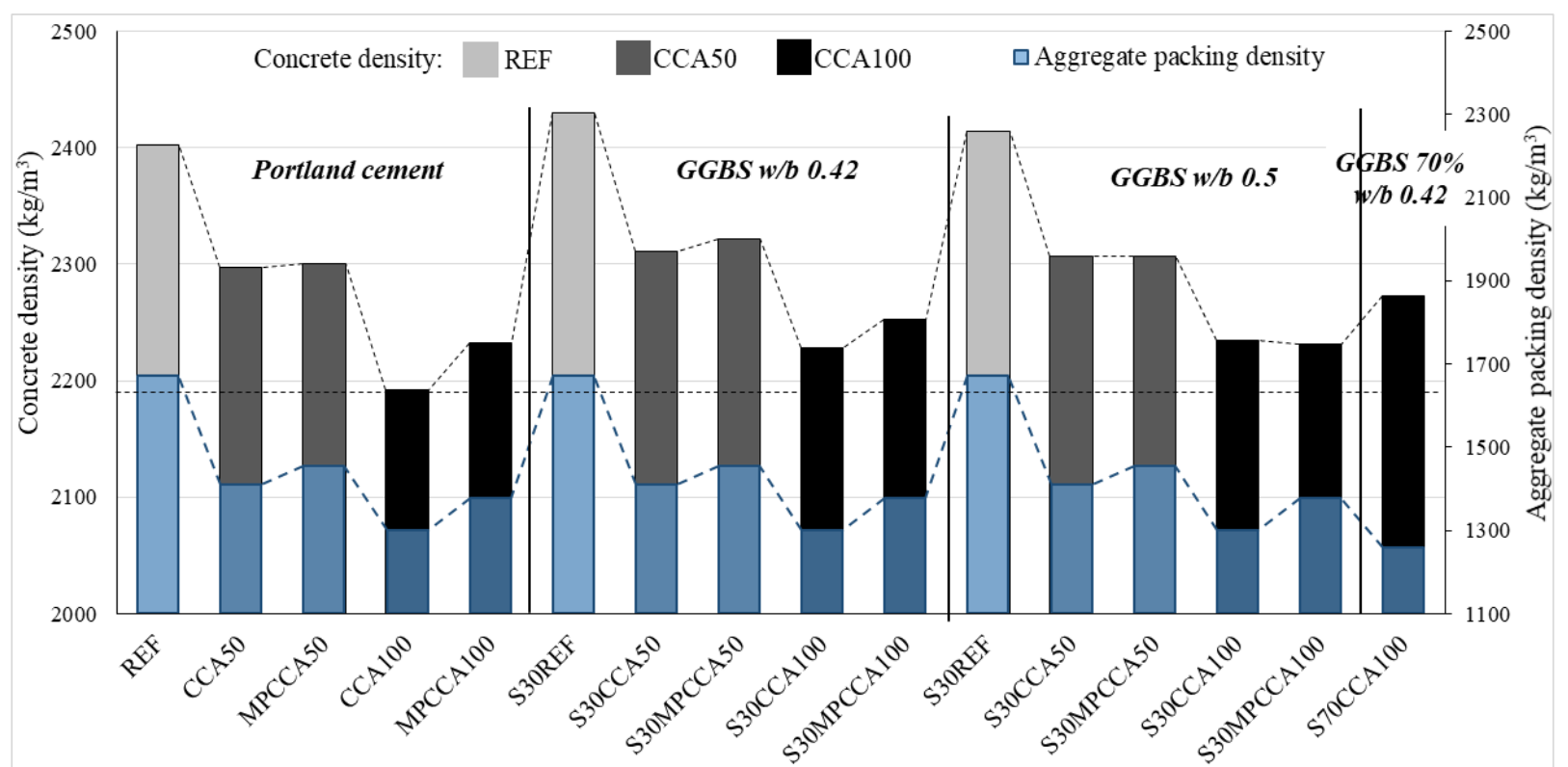

Figure 7 - Mean values of hardened concrete density, aggregate packing density 
By introducing more GGBS in mix S70CCA100 a part of the GGBS substitutes fine aggregates and thus leads to a lower packing density. Packing density of S70CCA100 mix is measured using GGBS as a fine aggregate replacement and is lower than packing density of other CCA100 alternatives owing to GGBS having lower density than fine CCA. Despite lower packing density concrete S70CCA100 shows highest density among other CCA100 concrete. This is understood as the GGBS replacing fine aggregates contributes still to the pozzolanic effect, building cement gel and leading to higher density of concrete. A micro-filler effect can be identified as the packing density is calculated for the S70CCA100 based on GGBS replacing fines and other CCA fractions. Thus, the GGBS has the possibility of coating and densifying the CCA which may also justify the observed lowering effect on packing density.

Across all CCA replacements, GGBS concrete shows slightly higher density compared to Portland cement alternatives due to better densification of cement paste by GGBS. Due to larger specific surface, smaller particle size than Portland cement and the strength building component C-S-H specific to GGBS is more dense than that from hydration of Portland cement [13, 41].

\subsection{Early age strength}

The pozzolanic reaction is boosted by an improved mixing method by pre-soaking GGBS in water, adapted from previous research [15].

The GGBS is pre-soaked in mixing water with $8 \%$ of total superplasticizer content in the mix. In this way GGBS is activated and made more prone to react with $\mathrm{CH}$ and form C-S-H earlier than with the ordinary mixing. As pointed out, even the micro-filler effect is occurring at early age. Therefore, the chemical activation by improved mixing method together with micro-filler effect contributes to increased early age strength. However, more investigation is required to discern these effects distinctly.

The 7-day compressive strength of CCA100 concrete in Figure 8 shown for improved mixing method with $30 \%$ GGBS replacement has equivalent effect as mechanical pre-processed CCA concrete. With the ordinary mixing method, the GGBS concrete does not reach the strength of mechanically pre-processed aggregates. The improved early strength gain is in agreement with Kim Y. et al. [42] who observe that concrete with 30\% slag replacement of Portland cement achieves $96 \%$ of the reference concrete strength at 7 days. A Swedish study shows that concrete containing $25 \%$ slag with CEMII-A/LL, the same cement in this study, shows only $95 \%$ of 7 day strength compared to the reference concrete although not with CCA [23]. Thus, it is obvious that a combination of mechanical pre-processed CCA with replacement of cement with GGBS should achieve $39 \mathrm{MPa}$, reference concrete strength. 


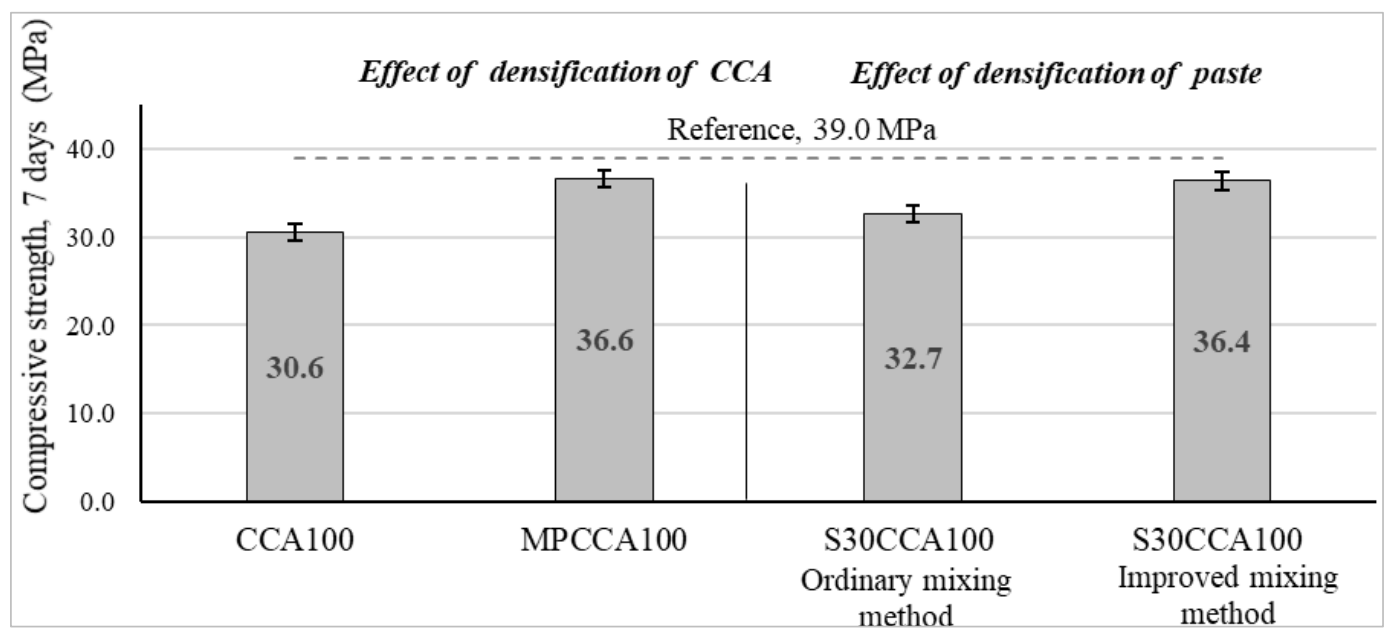

Figure 8-CCA concrete compressive strength at 7 days

\subsection{Comparison GGBS and Portland cement}

The 28-day compressive strength using 30\% GGBS replacements for water/binder ratio 0.5 same as reference, seen in Figure 9. It is known that CCA50, CCA100 concrete do not reach reference concrete strength level without mechanical pre-processing or GGBS addition. Introducing GGBS contributes to concrete compressive strength in the order REF > CCA100 > MPCCA100 > CCA50. GGBS shows maximum increase by $40 \%$ for reference concrete, this finding is consistent with previous research where at $30 \%$ GGBS replacement in natural aggregate concrete, the 28 day strength increases by $50 \%$ [43]. The CCA50 is not helped by GGBS addition, however mechanical pre-processing helps it to exceed reference concrete strength. However, the MPCCA50 has the highest scatter among the test results and therefore the benefit of GGBS cannot be realized as it is in the case of S30CCA50.

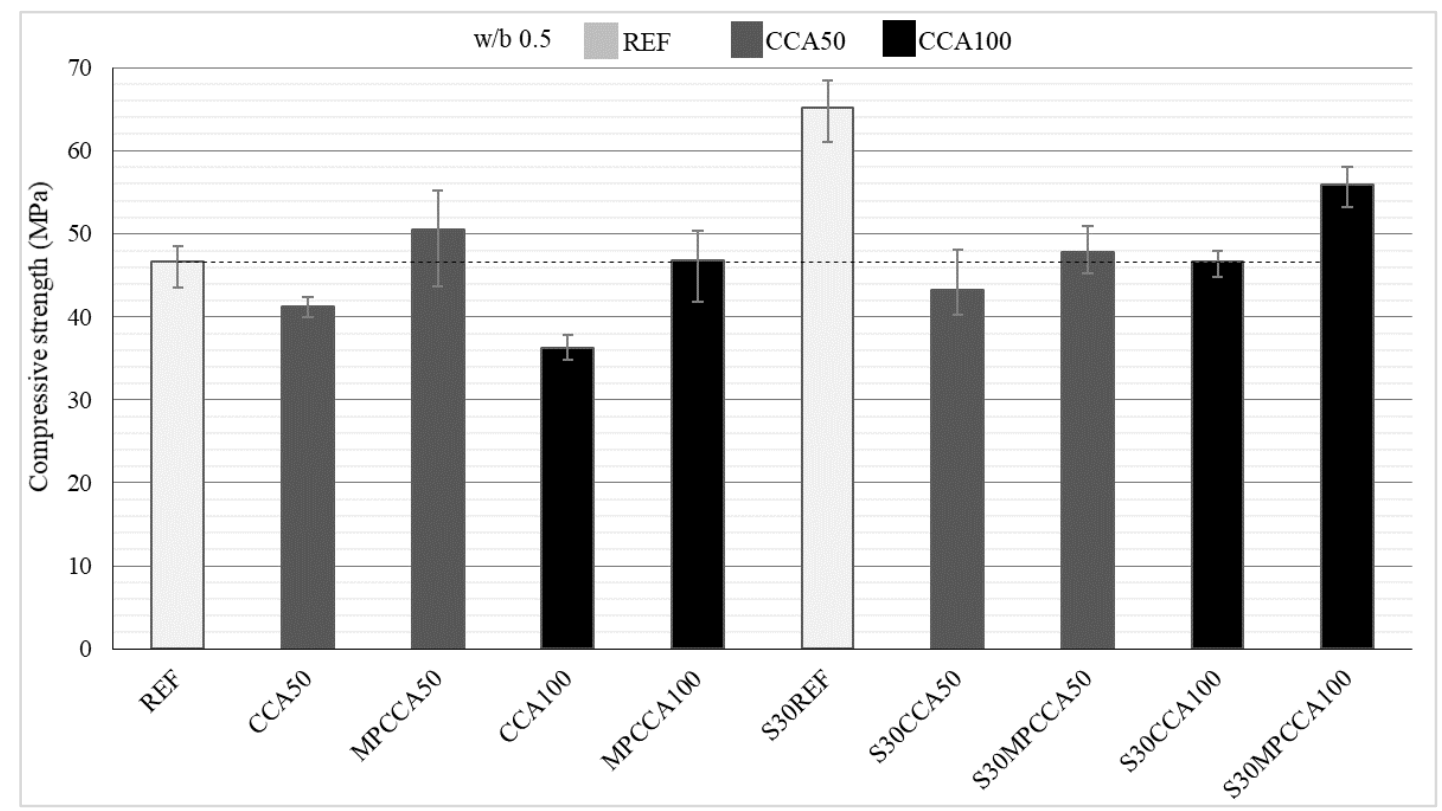

Figure $9-C C A-G G B S$ concrete compressive strength at 28 days, w/b ratio 0.5 
Gao J. M. et al. [16] attribute strength increase noticed in their results, to the densification of the microstructure at the aggregate-cement paste interface, which is due to GGBS having a larger specific surface than Portland cement $\left(425 \mathrm{~kg} / \mathrm{m}^{2}\right.$ and $361 \mathrm{~kg} / \mathrm{m}^{2}$ respectively).

The compressive strength of concrete mixes with GGBS are compared for low and medium water/binder ratios 0.42 and 0.5 respectively, shown in figure 10. The general observation is change in water/binder ratio induce differences in the range of 5-10 $\mathrm{MPa}$ in GGBS concrete. GGBS mixes with 100\% replacement of CCA show higher strength than 50\% CCA due to higher adhered mortar content. This is due to the fact that GGBS can seal the cracks in the adhered mortar and densify the aggregate-cement paste interface contributing to the increased strength [19]. The added effect of densified CCA and cement paste by results in higher strengths such as in S30MPCCA50 and S30MPCCA100.

The S70CCA100 where $12 \%$ of fine CCA is replaced with GGBS shows strength comparable to reference concrete with GGBS; findings are in agreement with previous research which shows CCA concrete containing 70\%GGBS shows higher 28-day compressive strength than reference concrete with Portland cement [10]. Corinaldesi V. et al. [11] show that compressive strength of CCA100 concrete surpasses reference concrete strength when silica fume replaces fine CCA.

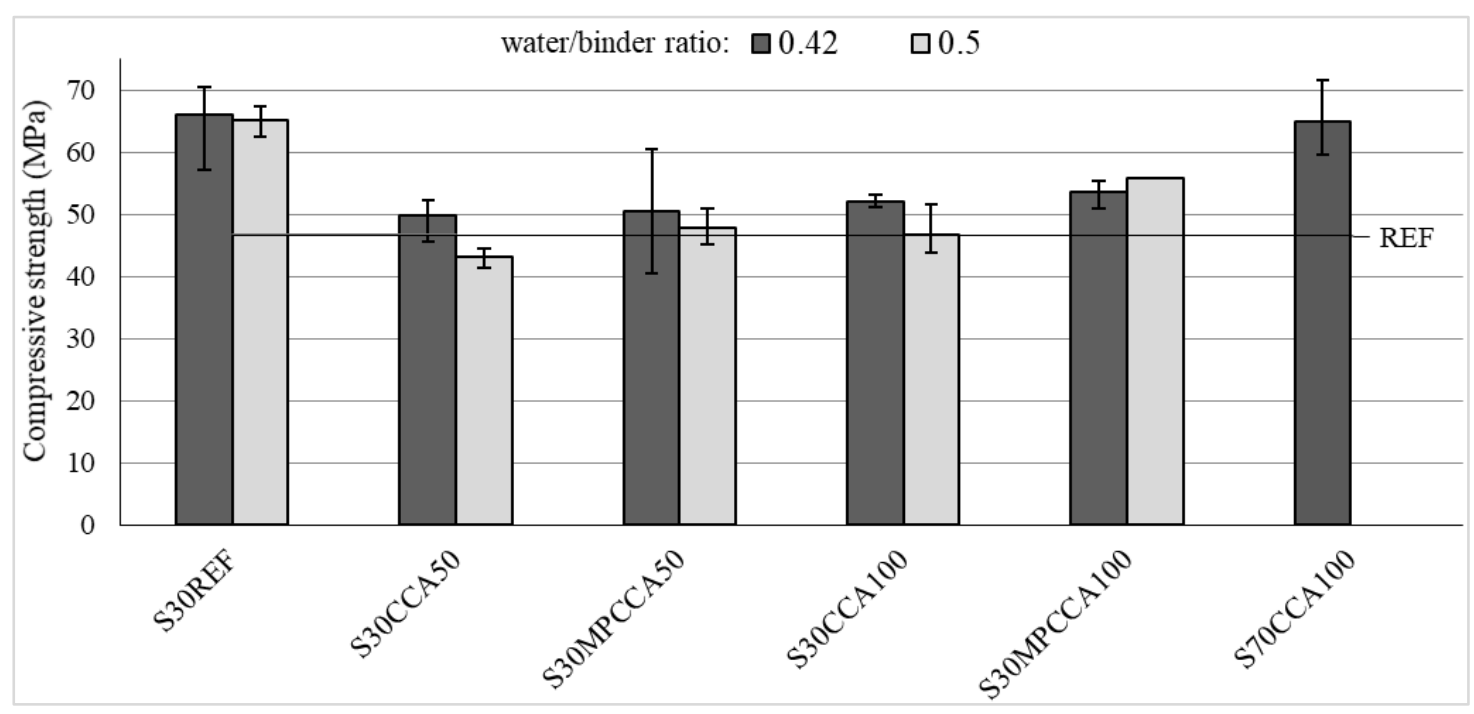

Figure $10-C C A-G G B S$ concrete compressive strength at 28 days, w/b ratios $0.42,0.5$

\section{5}

\section{Statistical significance of results}

The statistical significance is analysed for two main parameters - mechanical pre-processing and GGBS addition with 28-day compressive strength as response variable. This statistical analysis is shown for water/binder ratio of original concrete recipe, 0.5 . The claim of this study is to receive a strength and workability of CCA concrete likening reference concrete. The CCA100 mix with GGBS replacement reaches reference concrete strength of $46.6 \mathrm{MPa}$ and fulfils our claims. This is also fulfilled by mechanically pre-processed CCA50 mix with GGBS. 
The significance of mechanical pre-processing, GGBS addition or combination of both on CCA50, CCA100 mixes is statistically analysed using a two-sample T-test, Table 6. The sample mean is taken from Figure 10, mean and standard deviation is based on 3 specimens. It is seen for the case of CCA100, 30\% replacement of GGBS gives a significant result. While for CCA50 lowest p-value is achieved for mechanical pre-processing combined with GGBS replacement; meaning statistical significance maybe achieved for a larger sample size. For CCA100 combination of mechanical pre-processing with GGBS replacement would also give a significant result but it would mean extra energy input in the mechanical pre-processing.

Table 6 - Results of statistical analysis for $w / b$ 0.5, reference concrete strength $46.6 \mathrm{MPa}$

\begin{tabular}{|l|l|l|l|l|}
\hline Sample parameters & & $\begin{array}{l}\text { Mechanical pre- } \\
\text { processing }\end{array}$ & $\begin{array}{l}\text { GGBS } \\
\text { replacement }\end{array}$ & $\begin{array}{l}\text { Mechanical pre- } \\
\text { processing + GGBS } \\
\text { replacement }\end{array}$ \\
\cline { 2 - 5 } & CCA100 & MPCCA100 & S30CCA100 & S30MPCCA100 \\
\hline Mean & 35.17 & 46.82 & 46.74 & 55.88 \\
\hline Standard deviation & 1.50 & 4.42 & 1.71 & 2.47 \\
\hline P value & - & 0.050 & 0.003 & 0.001 \\
\hline T-test & - & 4.32 & 8.81 & 12.41 \\
\hline Significance & - & significant & significant & significant \\
\hline Sample parameters & CCA50 & MPCCA50 & S30CCA50 & S30MPCCA50 \\
\hline Mean & 41.3 & 47.06 & 43.21 & 47.76 \\
\hline Standard deviation & 1.21 & 6.14 & 4.2 & 2.87 \\
\hline P value & - & 0.256 & 0.543 & 0.07 \\
\hline T-test & - & 1.58 & 0.73 & 3.55 \\
\hline Significance & - & not significant & not significant & not significant \\
\hline
\end{tabular}

Analysing the effects of three factors, CCA replacement percentage, mechanical pre-processing and GGBS replacement on linear regressive coefficients of compressive strength shows that:

- Individual effects: mechanical pre-processing gives the largest effect followed by GGBS replacement $(7.76,5.79)$. CCA replacement percentage has no average influence.

- Interaction effects: CCA replacement percentage shows positive effect with GGBS replacement, highest effect seen for CCA100 (4.52), largest value is reached in combination with mechanical pre-processing.

It can be observed for CCA100 that either mechanical pre-processing or GGBS replacement, or a combination of both are equivalent in yielding reference concrete strength values. The replacement of $30 \%$ Portland cement by weight with GGBS results in $28 \%$ reduction of $\mathrm{CO}_{2 \text {,eqv }}$ emissions calculated for a cubic meter of the reference concrete recipe [44]. Therefore, a cementitious material replacement could be an option to produce likewise strong and climate optimized concrete. On the other hand, for CCA50 to reach reference concrete value, mechanical pre-processing has to be combined with GGBS replacement. It is estimated in Sadagopan [44] that excluding the washing activity, the $\mathrm{CO}_{2 \text {,eqv }}$ emissions resulting from mechanical preprocessing are negligibly small in comparison to $\mathrm{CO}_{2 \text {,eqv }}$ reductions from Portland cement replacement; $100 \mathrm{~g} \mathrm{CO}_{2 \text {,eqv }} / \mathrm{cum}, 102 \mathrm{~kg} \mathrm{CO}_{2, \text { eqv }} /$ cum respectively. Therefore, the decreasing effect on CCA50 strength by GGBS can be compensated in combination with mechanical pre-processing to produce a climate optimized concrete with a strength comparable to reference concrete. 
Blast furnace slag is introduced at $30 \%$ of cement weight in CCA concrete to densify cement paste to match the structural performance of reference concrete. Two CCA replacement scenarios are investigated, CCA50 where fines are replaced and CCA100 with overall replacement of aggregates. These two CCA replacement ratios are the most feasible ways of replacing aggregates in industrially active concrete recipes. It takes into account the logistics and the current state of affairs regarding production of concrete and amount of waste available. GGBS addition is made at two water/binder ratios 0.42 , and 0.5 .

Addition of GGBS is useful in CCA concrete because:

- Concrete density related to aggregate packing density: CCA100 with comparatively lower values of aggregate packing density and concrete density gives equal or higher strength than reference concrete with GGBS addition.

- Increased early age strength: the 7-day reference concrete strength is $7 \%$ away from reference concrete strength using with improved mixing method involving pre-soaking of GGBS

- Compressive strength at 28 days: for $0.42 \mathrm{w} / \mathrm{b}$ all CCA concrete alternatives give higher compressive strength than reference. At water/binder 0.5, CCA50 needs mechanical preprocessing to reach reference concrete strength.

- Fine aggregate replacement: introducing 70\% GGBS produces CCA100 concrete in a highstrength class

- Workability: in case of water/binder ratio 0.42 it brings CCA50, CCA100 concrete in the same flow class F2. Flow diameter of S70CCA100 comparable to self-compacted concrete.

- Climate optimized concrete: by replacing cement in addition to using recycled aggregates gives a more sustainable structural concrete.

Mechanical pre-processing is beneficial for CCA concrete because:

- Concrete density related to aggregate packing density: increases concrete density by increasing aggregate packing density, as there is a strong correlation in-between them.

- Increase early age strength: gives similar results as CCA100 mix with GGBS at 7 days.

- Compressive strength 28 days: CCA50, CCA100 reach reference concrete strength, mechanical pre-processing benefits CCA50 most when the mix contains GGBS.

- Workability: It generally helps CCA50, CCA100 to come down to the reference concrete flow class F2. In combination with GGBS same flow class F2 is maintained at water/binder 0.42.

- Climate optimized concrete: if not needed to be combined with GGBS to reach reference concrete strength, mechanical pre-processing is energy-craving process however optimized to 15 minutes to deliver quality CCA.

Statistical analysis on the compressive strength results confirms that for higher CCA replacements, GGBS addition is most beneficial. CCA50 is most benefitted by a combination of mechanical pre-processing and GGBS addition.

Using three modifications levels at CCA, at paste and at concrete mixing levels shows CCA concrete with $100 \%$ replacement and reduced cement content gives workability and compressive strength of same level or higher than reference concrete. 


\section{REFERENCES}

1. Chen C, Habert G, Bouzidi Y, Jullien A, and Ventura A: "LCA allocation procedure used as an incitative method for waste recycling: An application to mineral additions in concrete". Resources, Conservation and Recycling, 2010. 54(12): p. 1231-1240

2. Minunno R, O'Grady T, Morrison G M, Gruner R L, and Colling M: "Strategies for applying the circular economy to prefabricated buildings". Buildings, 2018. 8(9): p. 125

3. Svenska Miljö Emissions Data (SMED): "Avfall i Sverige 2018, Uppkomst och behandling", Naturvårdsverket, Editor. 2020, Naturvårdsverket: Stockholm. (In Swedish)

4. Sadagopan M, Malaga K, and Nagy A: "Modified pycnometer method to measure the water absorption of crushed concrete aggregates". Journal of Sustainable Cement-Based Materials, 2020: p. 1-11

5. Pepe M, Toledo Filho R D, Koenders E, and Martinelli E: "Alternative processing procedures for recycled aggregates in structural concrete". Construction and Building Materials, 2014. 69: p. 124-132

6. Katz A: "Treatments for the Improvement of Recycled Aggregate". Journal of Materials in Civil Engineering, 2004. 16(6): p. 597-603

7. Padmini A K, Ramamurthy K, and Mathews M S: "Influence of parent concrete on the properties of recycled aggregate concrete". Construction and Building Materials, 2009. 23(2): p. 829-836

8. Gutiérrez A and De Juan M: "Influence of Attached Mortar Content on the Properties of Recycled Concrete Aggregate". in International RILEM Conference on the Use of Recycled Materials in Buildings and Structures. 2004. Barcelona: RILEM Publications.

9. Sadagopan M, Malaga K, and Nagy A: "Improving recycled aggregate quality by mechanical pre-processing". Materials, 2020. 13(19)

10. Berndt M L: "Properties of sustainable concrete containing fly ash, slag and recycled concrete aggregate". Construction and Building Materials, 2009. 23(7): p. 2606-2613

11. Corinaldesi V. and Moriconi G, "Influence of mineral additions on the performance of 100\% recycled aggregate concrete". Construction and Building Materials, 2009. 23(8): p. 2869-2876

12. Mirzahosseini M and Riding K A: "Influence of different particle sizes on reactivity of finely ground glass as supplementary cementitious material (SCM)". Cement and Concrete Composites, 2015. 56: p. 95-105

13. Neville A M: "Properties of Concrete" 5th ed. 2013: Pearson Education

14. Svensk Byggtjänst: "Betonghandbok Material". Del 1. 3 ed. 2017, Stockholm: AB Svensk Byggtjänst. 540

15. Elaqra H A, Haloub M A A, and Rustom R N: "Effect of new mixing method of glass powder as cement replacement on mechanical behavior of concrete". Construction and Building Materials, 2019. 203: p. 75-82

16. Gao J M, Qian C X, Liu H F, Wang B and Li L: "ITZ microstructure of concrete containing GGBS". Cement and concrete research, 2005. 35(7): p. 1299-1304

17. Kong D, Lei T, Zheng J, Ma J, Jiang J, and Jiang J: "Effect and mechanism of surfacecoating pozzalanics materials around aggregate on properties and ITZ microstructure of recycled aggregate concrete". Construction and Building Materials, 2010. 24(5): p. 701708

18. Kou S C, Poon C S, and Chan D: "Influence of fly ash as a cement addition on the hardened properties of recycled aggregate concrete". Materials and Structures, 2008. 41(7): p. 11911201 
19. Kou S C, Poon C S, and Agrela F: "Comparisons of natural and recycled aggregate concretes prepared with the addition of different mineral admixtures". Cement and Concrete Composites, 2011. 33(8): p. 788-795

20. Letelier V, Tarela E, Osses R, Cárdenas J P, and Moriconi G: "Mechanical properties of concrete with recycled aggregates and waste glass". Structural Concrete, 2017. 18(1): p. 40-53

21. Nassar Roz-Ud-Din and Soroushian P: "Strength and durability of recycled aggregate concrete containing milled glass as partial replacement for cement". Construction and Building Materials, 2012. 29: p. 368-377

22. Kou S C, Poon C S, and Chan D: "Influence of fly ash as cement replacement on the properties of recycled aggregate concrete". Journal of materials in civil engineering, 2007. 19(9): p. 709-717

23. Esping O, Löfgren I, and Lindvall A: "Betongtekniska möjligheter med mineraliska tillsatsmaterial". Bygg \& Teknik, 2011. (In Swedish)

24. Kapoor K, Singh S P, and Singh B: "Durability of self-compacting concrete made with Recycled Concrete Aggregates and mineral admixtures". Construction and Building Materials, 2016. 128: p. 67-76

25. Kou S C and Poon C S: "Properties of self-compacting concrete prepared with coarse and fine recycled concrete aggregates". Cement and Concrete composites, 2009. 31(9): p. 622627

26. Liu S, Wang S, Tang W, Hu N, and Wie J: "Inhibitory Effect of Waste Glass Powder on ASR Expansion Induced by Waste Glass Aggregate". Materials (Basel, Switzerland), 2015. 8(10): p. 6849-6862. eng

27. Majhi R K and Nayak A N: "Production of sustainable concrete utilising high-volume blast furnace slag and recycled aggregate with lime activator". Journal of Cleaner Production, 2020. 255: p. 120188

28. Sriravindrarajah R, Wang N D H., and Ervin L J W: "Mix design for pervious recycled aggregate concrete". International Journal of Concrete Structures and Materials, 2012. 6(4): p. 239-246

29. Ljungkrantz C, Möller G, and Petersons N, "Betong-handbok Material". 2 ed. 1994, Stockholm: AB Svensk Byggtjänst. (In Swedish)

30. Djelloul O, Menadi B, Wardeh G, and Kenai S, "Performance of self-compacting concrete made with coarse and fine recycled concrete aggregates and ground granulated blastfurnace slag". Advances in Concrete Construction, 2018. 6: p. 103-121

31. Powers T C: "Structure and Physical Properties of Hardened Portland Cement Paste". Journal of the American Ceramic Society, 1958. 41(1): p. 1-6

32. Khodair Y and Bommareddy B: "Self-consolidating concrete using recycled concrete aggregate and high volume of fly ash, and slag". Construction and Building Materials, 2017. 153: p. 307-316

33. Limbachiya M C, Leelawat $\mathrm{T}$, and Dhir R K: "Use of recycled concrete aggregate in highstrength concrete". Materials and structures, 2000. 33(9): p. 574

34. Guo Z, Jiang T, Zhang J, Kong X, Chen C, and Lehman D E: "Mechanical and durability properties of sustainable self-compacting concrete with recycled concrete aggregate and fly ash, slag and silica fume". Construction and Building Materials, 2020. 231: p. 117115

35. Xiao J, Lei B, and Zhang C: "On carbonation behavior of recycled aggregate concrete". Science China Technological Sciences, 2012. 55(9): p. 2609-2616

36. CEMENTA AB: "Product specification- Byggcement CEM II/A-LL 42,5 R". 2018: Stockholm

37. SSAB Merox AB: "Merit 5000 Product specification". 2002 [cited; Available from: https://www.merox.se/uploads/images/345/Produktspec Merit 5000 utg 03.pdf 
38. Tam Vivian W Y, Gao X F, and Tam C M: "Microstructural analysis of recycled aggregate concrete produced from two-stage mixing approach". Cement and Concrete Research, 2005. 35(6): p. 1195-1203

39. Guo Z, Zhang J, Jiang T, Jiang T, Chen C, Bo R, and Sun Y: "Development of sustainable self-compacting concrete using recycled concrete aggregate and fly ash, slag, silica fume". European Journal of Environmental and Civil Engineering, 2020: p. 1-22

40. Lima C, Caggiano A, Faella C, Martinelli E, Pepe M and Realfonzo R: "Physical properties and mechanical behaviour of concrete made with recycled aggregates and fly ash". Construction and Building Materials, 2013. 47: p. 547-559

41. Virgalitte S J, Luther M D, Rose J H, Mather B, Bell L W, Ehmke B A, Klieger P, Roy D M, Call B M, and Hooton R D: "Ground Granulated Blast-Furnace Slag as a Cementitious Constituent in Concrete". American Concrete Institute ACI Report 233R-95, 1995

42. Kim Y, Hanif A, Usman M, Munir M J, Kazmi S M S, and Kim S: "Slag waste incorporation in high early strength concrete as cement replacement: Environmental impact and influence on hydration \& durability attributes". Journal of Cleaner Production, 2018. 172: p. 3056-3065

43. Oner A and Akyuz S: "An experimental study on optimum usage of GGBS for the compressive strength of concrete". Cement and Concrete Composites, 2007. 29(6): p. 505514

44. Sadagopan M: "Recycling of concrete in new structural concrete", in Bulletin No.117 (PhD Thesis), University of Borås. 2021 